\title{
Neoadjuvant chemotherapy prior to preoperative chemoradiation or radiation in rectal cancer: should we be more cautious?
}

\author{
R Glynne-Jones*,', J Grainger', M Harrison', P Ostler' and A Makris' \\ 'Mount Vernon Cancer Centre, Northwood, Middlesex, HA6 2RN, UK
}

\begin{abstract}
Neoadjuvant chemotherapy (NACT) is a term originally used to describe the administration of chemotherapy preoperatively before surgery. The original rationale for administering NACT or so-called induction chemotherapy to shrink or downstage a locally advanced tumour, and thereby facilitate more effective local treatment with surgery or radiotherapy, has been extended with the introduction of more effective combinations of chemotherapy to include reducing the risks of metastatic disease. It seems logical that survival could be lengthened, or organ preservation rates increased in resectable tumours by NACT. In rectal cancer NACT is being increasingly used in locally advanced and nonmetastatic unresectable tumours. Randomised studies in advanced colorectal cancer show high response rates to combination cytotoxic therapy. This evidence of efficacy coupled with the introduction of novel molecular targeted therapies (such as Bevacizumab and Cetuximab), and long waiting times for radiotherapy have rekindled an interest in delivering NACT in locally advanced rectal cancer. In contrast, this enthusiasm is currently waning in other sites such as head and neck and nasopharynx cancer where traditionally NACT has been used. So, is NACT in rectal cancer a real advance or just history repeating itself? In this review, we aimed to explore the advantages and disadvantages of the separate approaches of neoadjuvant, concurrent and consolidation chemotherapy in locally advanced rectal cancer, drawing on theoretical principles, preclinical studies and clinical experience both in rectal cancer and other disease sites. Neoadjuvant chemotherapy may improve outcome in terms of disease-free or overall survival in selected groups in some disease sites, but this strategy has not been shown to be associated with better outcomes than postoperative adjuvant chemotherapy. In particular, there is insufficient data in rectal cancer. The evidence for benefit is strongest when NACT is administered before surgical resection. In contrast, the data in favour of NACT before radiation or chemoradiation (CRT) is inconclusive, despite the suggestion that response to induction chemotherapy can predict response to subsequent radiotherapy. The observation that spectacular responses to chemotherapy before radical radiotherapy did not result in improved survival, was noted 25 years ago. However, multiple trials in head and neck cancer, nasopharyngeal cancer, non-small-cell lung cancer, small-cell lung cancer and cervical cancer do not support the routine use of NACT either as an alternative, or as additional benefit to CRT. The addition of NACT does not appear to enhance local control over concurrent CRT or radiotherapy alone. Neoadjuvant chemotherapy before CRT or radiation should be used with caution, and only in the context of clinical trials. The evidence base suggests that concurrent CRT with early positioning of radiotherapy appears the best option for patients with locally advanced rectal cancer and in all disease sites where radiation is the primary local therapy. British Journal of Cancer (2006) 94, 363-37I. doi:I0.1038/sj.bjc.6602960 www.bjcancer.com
\end{abstract} (C) 2006 Cancer Research UK

Keywords: rectal cancer; neoadjuvant chemotherapy; chemoradiation

The term neoadjuvant chemotherapy (NACT) was suggested over 20 years ago (Frei, 1982). Given that tumour size is a predictor of outcome in most disease sites, NACT has often been proposed with the aim or reducing the gross tumour burden before surgery, radiation or chemoradiation (CRT). The original hypothesis proposed that neoadjuvant cytotoxic chemotherapy could shrink a locally advanced tumour, and thereby allow more effective local therapy. Reducing the size of a tumour may facilitate a curative surgical resection. Also, in general, smaller cancers may be more oxygenated, and hence easier to control with radiation (Fletcher, $1980,1984)$. Since then, the breadth of treatment possibilities has been extended as more effective combinations of cytotoxic chemotherapy and more recently new molecular targets that

*Correspondence: Dr R Glynne-Jones; E-mail: rob.glynnejones@nhs.net Revised 16 December 2005; accepted 16 December 2005 potentially reduce the risks of metastatic disease have been introduced.

In stages II and III of rectal cancer the optimal multimodality management remains an increasing challenge. Surgery remains the mainstay of treatment, but a high risk of local recurrence and poor survival ( $40-55 \%$ at 5 years) has been reported even for patients with mobile/resectable rectal cancer despite a curative resection and postoperative CRT (Tepper et al, 2002). Despite improved local surgical and radiotherapeutic techniques, locoregional relapse is now exceeded by the rate of development of systemic metastases. The Dutch rectal cancer study, CKVO 95-04, which randomised between surgery alone and short-course preoperative radiotherapy followed by immediate surgery, found local regional control improved from 91.6 to $97.6 \%$ at 2 years with preoperative radiotherapy (Kapiteijn et al, 2001). However, the rate of metastatic disease was $18 \%$ in both arms at 2 years. Despite low 
rates of local recurrence, $25-35 \%$ of patients with rectal cancer still eventually die from metastatic disease. In patients with unresectable disease (Frykholm et al, 2001) both local control and metastatic disease remain issues.

There is increasing enthusiasm for preoperative CRT in the management of rectal cancer. The advantage of using radiotherapy in the preoperative setting includes the potential to increase the likelihood of a R0 resection; to reduce the risk of tumour seeding; less acute toxicity; and enhanced radio-sensitivity because of better oxygenated cells as opposed to hypoxic cells in scar tissue; and an improved chance of sphincter preservation achieved by downstaging the tumour. Finally, compliance to treatment may be more easily achieved in the preoperative compared to the postoperative setting.

Recent data from studies in advanced/metastatic colorectal cancer show high response rates to combination cytotoxic chemotherapy (Cassata et al, 2001; Cassidy et al, 2004). Three drug combinations of 5-fluorouracil (5FU), oxaliplatin and irinotecan may now give even higher response rates in the region of 75\% (Calvo, 2002; Falcone et al, 2002; Ychou et al, 2003). This evidence of efficacy coupled with the introduction of novel molecular targeted therapies (Saltz et al, 2002; Cho et al, 2003; Cunningham et al, 2004; Tabernero et al, 2004), has heightened an interest in delivering NACT in locally advanced rectal cancer Where there are delays (as in the UK) in starting CRT or RT, because of a lack of resources, the use of NACT is appealing. It seems plausible that that NACT might compensate for these delays, and enhance both local and systemic control, halt further tumour progression in addition to reducing patient anxiety. However, there is no evidence to support this approach. In contrast, this new enthusiasm appears currently waning in other sites such as head and neck and nasopharynx cancer where traditionally NACT has been used (Garden, 2005).

With the aim of reducing systemic micrometastases, the use of neoadjuvant combination chemotherapy using oxaliplatin and 5FU before CRT has been explored in rectal cancer (Calvo et al, 2003; Chau et al, 2005). A Spanish study (Calvo et al, 2003) explored a short, intense induction regimen of oxaliplatin and 5FU (FOLFOX 4) before conventional CRT, which appeared to improve the tumour downstaging when compared to historical results in their unit previously achieved with CRT alone. This strategy of NACT claims to achieve a $29 \%$ complete pathological response rate in locally advanced rectal cancer. Studies from the UK have shown that similar neoadjuvant drug combinations in locally advanced rectal cancer can be delivered without apparently compromising future compliance to CRT (Chau et al, 2003, 2005).

Not all clinically localised cancers can be cured by radiation alone. Larger, more advanced cancers are more difficult to control locally than smaller ones and require higher doses of radiation (Fletcher, 1980; Perez et al, 1998). It is well recognised that factors such as hypoxia, which are often a consequence of rapid tumour growth have a negative impact on local control and survival from radiation therapy (Fyles et al, 1998; Nordsmark and Overgaard, 2000). Additionally, patients with more advanced tumours also are at a higher risk of systemic metastases. Hypoxia-driven cellular mechanisms may also contribute to a poor outcome, producing a more aggressive locoregional disease, and promotion of invasive capacity and angiogenesis (Walenta et al, 2000; Brizel et al, 2001). It has always been supposed that the anticancer effects of radiotherapy are mediated through oxygen associated free radical production (Hall, 2000). Others have stressed the importance of the overall time factor in combined modality treatment of head and neck cancer (Peters and Withers, 1997) in that accelerated repopulation can occur for any clonogens surviving a therapeutic intervention. Owing to this, novel treatment strategies have been devised. These aim to improve local and distant control. A number of biological rationales have been developed, including reducing the duration of potential maximum cellular proliferation by increasing the dose and intensity of treatment during the latter part of radiotherapy, or the addition of concurrent chemotherapy. An alternative strategy has been to use more intensive neoadjuvant or postoperative adjuvant chemotherapy. Consequently, combinations of sequential or concurrent chemotherapy and external beam irradiation have been in clinical use since the 1980s.

For the purpose of this article, chemotherapy should be considered as 'neoadjuvant' if it is administered as induction before radiotherapy, 'concurrent' if administered during the course of radiotherapy and 'consolidation' if delivered after radiation or CRT. In this review, we aim to explore the advantages and disadvantages of these separate approaches both in rectal cancer and other disease sites.

\section{MATERIALS AND METHODS}

A literature search was performed using Medline and Cancerlit over the period 1996-2005 supplemented by hand searching of abstracts from the proceedings of the American Society of Clinical Oncology meetings to provide evidence for this discussion. Several keywords have been used which include synchronous, neoadjuvant, induction, concurrent, consolidation chemotherapy, CRT, radiotherapy and cancer.

\section{Neoadjuvant chemotherapy}

Advantages There are many theoretical advantages to NACT, which include the potential to eradicate distant micrometastases at an early stage in the evolution of the disease, utilization of the embryonic tumour blood supply and treatment of a fit patient, before, not after the depredations of surgery. In contrast, in the postoperative setting the patient is often unfit, and there is a significant chance of hypoxia within surgical scars or any residual disease. There is also evidence that the primary tumour without metastatic disease may be more sensitive to chemotherapy than metastatic lesions (Von Hoff et al, 1986; Maehara et al, 1990).

Tumour shrinkage with chemotherapy potentially allows improved tumour vascularity. Theoretically, the consequences of this are improved oxygenation and higher intratumoural levels of cytotoxic drugs - although there is only scanty data to confirm this hypothesis (Milas et al, 1995; Taghian et al, 2005). This is not just an issue of the tumour getting smaller, since it would also be expected that significant cell loss with cytotoxic chemotherapy may lead to a reduction in oxygen consumption (Milas et al, 1995). These factors of better oxygenation and improved drug access from a lower interstitial pressure (Taghian et al, 2005) in turn may enhance tumour sensitivity to chemotherapy or radiation. In addition, in the clinic, oncologists endorse the use of NACT to reduce the primary tumour volume and consequently reduce the high-dose radiation volume. This change in field size can allow avoidance of the tolerance dose for critical structures.

Randomised trials have established a well-defined role for NACT before surgical resection both to promote resectability and to allow more conservative surgery in primary breast cancer (Mauriac et al, 1991; Scholl et al, 1994; Makris et al, 1998; van der Hage et al, 2001; Bear et al, 2003). However, these trials in breast cancer have shown that there is no impact on survival whether the chemotherapy schedule is delivered before or after surgery. This strategy of NACT has also been used in head and neck cancer (The Department of Veterans Affairs Laryngeal Cancer Study Group, 1991; Lefevre et al, 1996), where it has resulted in significant downstaging of a locally advanced tumour, and allowed more patients to undergo a curative resection (Spaulding et al, 1994). However, the combination of NACT followed by radiotherapy was found to be inferior to concomitant CRT for organ preservation (Forrestiere et al, 2003). 
There are several reasons that some researchers wish to deliver chemotherapy and radiotherapy at different times. First, the interaction between chemotherapy and radiotherapy often gives rise to such a marked increase in acute toxicity that it is necessary to reduce the dose and intensity of chemotherapy. Neoadjuvant chemotherapy may be associated with better compliance to treatment, and enable full systemic doses of chemotherapy to be delivered. In contrast, the effectiveness of adjuvant treatment in the postoperative setting has frequently been compromised by poor tolerance and marked dose reductions in oesophageal and rectal cancer.

NACT may act in some ways as a selection manoeuvre. There always exists a subset of patients with a very aggressive natural history, who are likely to fail to respond to chemotherapy. The delay before surgery means that patients who fail to respond locally, progress and may develop metastatic disease (Rohatgi et al, 2005) or deteriorate because of excess toxicity, can be selected out. These groups have no real possibility of benefit and can be spared the rigours of surgery or radical CRT.

A major advantage of NACT lies in the ability to observe and evaluate tumour clinical response during treatment. It is therefore often argued that response is a good testing ground for novel chemotherapy combinations, and that response to NACT can define good and bad prognostic groups - although these patients may well have a favourable outcome anyway. In contrast to crude measures like size on CT scans, the use of sequential positron emission tomography may define a major metabolic response to CRT (Guillem et al, 2004), and offers the opportunity to predict a better outcome in terms of overall survival. Failure to respond enables the delivery of a noncross resistant chemotherapy in breast cancer, as has been used in the Aberdeen neoadjuvant trial in breast cancer (Smith et al, 2002). However, in rectal cancer crossover studies at progression of first-line therapy have shown low rates of response to second-line chemotherapy (Tournigand et al, 2004).

Disadvantages Induction chemotherapy will delay the definitive local treatment. Radiobiological evidence suggests that the potential doubling time of clonogenic cells can reach their maximum potential if cell loss is abolished (Kummermehr et al, 1992). Thus, by adding 9-12 weeks to the overall duration of treatment with 3-4 cycles of induction chemotherapy, tumour cell production could actually increase even if the volume of tumour on CT scanning appears less (Withers et al, 1988). Other authors have raised concerns regarding the time factor, and how preoperative chemotherapy may fail to take into account radiobiological principles of repopulation (Peters and Withers, 1997). NACT can accelerate the kinetics of tumour proliferation in residual cells, since it is observed that sequential responses from multiple lines of chemotherapy become shorter in duration.

As it is recognised that only a proportion of patients will respond to NACT, those who fail to respond in a large proportion of the cells are more likely to develop resistant cells. This process favours the selection of radio-resistant clones, and may reduce the efficacy of subsequent radiotherapy. In addition, if neo-adjuvant chemotherapy inhibits apoptotic pathways, then it may render what are normally apoptosis prone tumour cells less sensitive to radiation. It is also well recognised that chemotherapy may in some tumours upregulate epidermal growth factor receptor (EGFR) expression (De Pas et al, 2004), which in turn promotes angiogenesis, affects stromal proliferation, and may make the tumour more radio-resistant. Thus short-term response may not improve long-term outcome.

In cervical cancer, at least seven randomised trials have compared neoadjuvant cisplatin containing induction chemotherapy plus radiation therapy with radiation therapy alone (Chauvergne et al, 1990; Souhami et al, 1991; Tattersall et al, 1992; Kumar et al, 1994; Tattersall et al, 1995; Sundfor et al, 1996; Leborgne et al, 1997). These have consistently failed to show an improvement in overall or disease-free survival. In two trials (Souhami et al, 1991; Tattersall et al, 1992) results of NACT were significantly worse. It has been conjectured that this is a result of reducing compliance to the radiotherapy component and possibly enhancing accelerated repopulation of resistant clones with induction chemotherapy.

NACT especially in long courses (3-4 cycles) also may allow time for these drug-resistant clones to migrate from the primary site and seed distant or potential sanctuary sites. In small-cell lung cancer, where high responses to chemotherapy are observed, there is a significant increase in the incidence of brain metastases in patients receiving late compared to early thoracic radiotherapy, and a worse overall survival (Murray et al, 1993).

Finally, compliance to the CRT phase may be reduced if severe toxicity is experienced with NACT (Table 1).

\section{Concurrent chemotherapy}

In rectal cancer there have been many different concurrent CRT schedules evaluated in phase I/II studies. Most researchers have used either a continuous infusion of 5FU (Rich et al, 1995), or the oral fluoro-pyrimidines (Hoff et al, 2000; Dunst et al, 2002; Kim et al, 2002; Dunst et al, 2004). Other more recent trials have integrated oxaliplatin into the CRT schedule (Rosenthal et al, 2002; Rodel et al, 2003; Glynne-Jones et al, 2004), and also irinotecan (Michell et al, 2001; Kennedy et al, 2004; Hofheinz et al, 2005).

The evidence base in terms of randomised trials of concurrent CRT in rectal cancer is limited. The North American standard of care in rectal cancer is to deliver postoperative chemotherapy and CRT to patients staged postoperatively as $\mathrm{T} 3 / 4$ or $\mathrm{N}+$. This policy has been defined within the NIH consensus statement in 1990 based on the results of two pivotal randomised American studies (GTSG 7175 and NCCTG 79/47/51) (Gastrointestinal Tumor Study Group, 1985; Krook et al, 1991). The NSABP RO2 study (Wolmark et al, 2000), showed that the addition of radiotherapy produced

Table I Neoadjuvant chemotherapy

\begin{tabular}{|c|c|}
\hline Potential advantages & Potential disadvantages \\
\hline Early treatment of micrometastases & Increase in duration of chemotherapy \\
\hline Tumour will have intact blood supply & Delays definitive treatment \\
\hline Delivery of full systemic doses & Favours development of resistant clones \\
\hline Better compliance to chemotherapy treatment & May select radio-resistant clones \\
\hline May enhance oxygenation and radio-responsiveness & May allow distant/sanctuary site seeding \\
\hline May allow radical RT if tumour shrinks & May reduce compliance to chemoradiation \\
\hline \multicolumn{2}{|l|}{ Potential for organ sparing if downstaged } \\
\hline \multicolumn{2}{|l|}{ Potential for curative resection if downstaged } \\
\hline \multicolumn{2}{|l|}{ Avoids surgery for resistant/rapidly progressive tumours } \\
\hline \multicolumn{2}{|l|}{ Response to chemo predictive of response to radiation } \\
\hline Response may define good/bad prognostic groups & \\
\hline
\end{tabular}


significantly less locoregional failure as a first event ( 8 vs $13 \%$ at 5 years) compared to adjuvant chemotherapy alone. However, the addition of radiotherapy did not influence overall relapse-free or disease-free survival.

A further European randomised trial of postoperative 5FUbased CRT against surgery alone in Dukes B and C rectal cancer to a dose of $46 \mathrm{~Gy}$ demonstrated a significant improvement in local control, disease-free survival and overall survival for postoperative CRT (Tveit et al, 1997).

On the basis of this evidence, many mainland European countries have extrapolated the North American approach to the preoperative setting and deliver CRT to patients who are considered $\mathrm{T} 3 / 4$ or $\mathrm{N}+$ on the basis of preoperative transrectal ultrasound. In France in 1994, a national consensus statement recommended the use of preoperative CRT in T3 and resectable T4 rectal cancer (Conference de consensus, Paris 1994).

A recent German phase III trial randomised 823 patients between preoperative CRT and postoperative CRT (patients received postoperative adjuvant chemotherapy in both arms of this trial). This study convincingly showed an improved therapeutic ratio for preoperative treatment. Local recurrence, acute and late toxicity were all statistically significantly reduced with the preoperative approach (Sauer et al, 2004). There was, however, no difference in the distant metastases rate or overall survival.

Two recent large trials have (from the EORTC and FFCD groups), have compared preoperative radiotherapy alone with preoperative CRT (Bosset et al, 2005a, b; Gerard et al, 2005). The former trial has also used a second randomisation to compare postoperative adjuvant 5FU chemotherapy following CRT vs no further treatment (Bosset et al, 2005a). Both trials demonstrated a highly signigficant reduction in the risks of local recurrence, but showed no impact on metastases, disease-free survival or overall survival.

In addition two small randomised trials of CRT in the postoperative adjuvant setting also support the view that concurrent chemotherapy is the most effective strategy (Fountzilas et al, 1999; Cafiero et al, 2003). The first paper questions the additional advantage to consolidation chemotherapy following the main strategy of concurrent CRT. In contrast the data from Cafiero suggest that the beneficial results of concurrent CRT may not apply if these modalities are administered sequentially rather than concurrently.

Advantages Prolongation of overall radiotherapy time allows accelerated repopulation. Concurrent CRT schedules therefore appear more efficient and may well offer more advantage in terms of locoregional control if our current hypotheses regarding accelerated tumour cell proliferation are correct. It is recognised that the rate of tumour growth is slower than the potential doubling time of tumour cells reflecting the cell loss factor. Cell production rates can be approximately 10 times faster than tumour growth rates (Trott, 1999). Repopulation is probably accounted for both by a decrease in the cell loss factor and in an increase in the rate of proliferation of surviving tumour cells (Fowler, 1991). Many consider that the increase in cellular repopulation relates both to increase in tumour oxygen and also cellular density changes. The advantage of the concurrent administration of radiotherapy and chemotherapy is that it may prevent the tumour repopulating.

In non-small-cell lung cancer (NSCLC), randomised studies comparing sequential $v s$ concurrent treatment have shown an advantage to the concurrent approach; perhaps not surprisingly, there is an associated greater toxicity. Both Curran et al (2000) and Furuse et al (1999), as well as a recent preliminary report (Choy et al, 2002), have shown an advantage to early CRT followed by consolidation chemotherapy in terms of median survival over both induction followed by concurrent and sequential chemotherapy and radiotherapy. Individual trials have also demonstrated an overall survival benefit for concurrent CRT over sequential chemotherapy and radiation or radiation alone in nasopharyngeal cancer (NPC) of about 30\% (Al-Sarraf et al, 1998; Chan et al, 2002; Lin et al, 2003).

A recently reported phase III trial (Forrestiere et al, 2003) randomised patients with locally advanced laryngeal cancer into three study groups. The first group received induction chemotherapy with cisplatin plus 5FU $120 \mathrm{~h}$ infusion every 3 weeks for 23 courses depending on response followed by radical radiotherapy. The second group received radiotherapy with concurrent administration of cisplatin at a dose of $100 \mathrm{mg} \mathrm{m}^{-2}$ on days 1,22 and 43 but without any induction chemotherapy. The third group received radiotherapy alone. A total of 540 patients were randomly assigned to one of these three groups. Locoregional control was significantly better with concurrent cisplatin and radiotherapy (78 vs 61\% for induction chemotherapy followed by radiotherapy). In addition $91 \%$ of patients who received induction chemotherapy were metastasis-free compared to $92 \%$ of those who received concurrent chemotherapy and radiotherapy. However, overall survival rates were similar in all three groups. The study concludes that radiotherapy with concurrent cisplatin should be the standard of care for patients who wish to preserve their larynx. The routine use of induction chemotherapy followed by radiotherapy in head and neck cancer is therefore not supported by the results of this trial.

Concurrent chemotherapy potentially introduces systemic doses of chemotherapy early at the same time as the intensive treatment of the primary tumour. Early chemotherapy will hopefully stop repopulation and downregulate any angiogenic mechanisms, which in turn may help to prevent metastases. There is an obvious potential that greater toxicity will result from concurrent chemotherapy.

Disadvantages Concurrent chemotherapy may be associated with a high risk of enhanced acute toxicity, in part because chemotherapy may inhibit the ability of normal tissue to repair the sublethal radiation induced damage. In order to avoid excess toxicity, most clinicians have resorted to lower doses of chemotherapy and a maximum of two drugs. However, lower doses of chemotherapy imply less systemic effects on reducing metastatic disease. An alternative strategy is to reduce the total dose of radiotherapy, although this practice too has been criticised on the grounds of delivering an inadequate dose. Concurrent chemotherapy and radiotherapy may be associated with more acute and dose limiting toxicity, and also more late toxicity (Table 2).

\section{Consolidation chemotherapy}

A third strategy (consolidation chemotherapy) is to deliver chemotherapy late in the process of radiotherapy or shortly after its completion. The role of using a consolidation chemotherapy schedule is currently being explored in the United Kingdom ACT II trial in anal cancer where patients are randomised to two courses of $5 \mathrm{FU} /$ cisplatin following the completion of CRT or no further treatment (James and Meadows, 2003). This policy is also likely to be explored in rectal cancer in a planned American ACOSOG study.

Advantages Shrinking the tumour with radiotherapy may allow improved tumour vascularity and facilitate high levels of cytotoxic drugs reaching any remaining tumour cells. It is also possible that the small percentage of clonogenic tumour cells that manage to survive to the end of radiotherapy may be partially damaged but more actively proliferating and may have increased susceptibility to cytotoxic chemotherapy. In addition the high rate of failure in terms of distant metastases, suggests that residual malignant cells either in the primary site or elsewhere may require more effective and additional systemic methods of elimination if cure is to be achieved. 
Table 2 Concurrent chemotherapy (chemoradiation - CRT)

\begin{tabular}{|c|c|}
\hline Potential advantages & Potential disadvantages \\
\hline Early treatment of micrometastases & Delivery of less than full systemic doses \\
\hline May prevent repopulation during radiotherapy & Worse compliance to chemotherapy treatment \\
\hline Tumour will have intact blood supply & More acute toxicity? \\
\hline Potential for organ sparing if downstaged & More late toxicity? \\
\hline \multicolumn{2}{|l|}{ Potential for curative resection if downstaged } \\
\hline \multicolumn{2}{|l|}{ Avoids surgery for resistant/progressive tumours } \\
\hline \multicolumn{2}{|l|}{ Response may define good/bad prognostic groups } \\
\hline \multicolumn{2}{|l|}{ Trials show improved local control } \\
\hline Trials show reduced rates of metastatic disease & \\
\hline
\end{tabular}

Table 3 Consolidation chemotherapy in addition to chemoradiation (CRT)

\begin{tabular}{|c|c|}
\hline Potential advantages & Potential disadvantages \\
\hline $\begin{array}{l}\text { Early treatment of micrometastases } \\
\text { May prevent repopulation during radiotherapy } \\
\text { Tumour will have intact blood supply } \\
\text { May enhance oxygenation and chemo-responsiveness } \\
\text { Delivery of full systemic doses? } \\
\text { Cells may be more sensitive to chemotherapy } \\
\text { Potential for organ sparing if downstaged } \\
\text { Potential for curative resection if downstaged } \\
\text { Avoids surgery for resistant/progressive tumours } \\
\text { Response may define good/bad prognostic groups } \\
\text { Trials show improved local control from CRT } \\
\text { Trials show reduced rates of metastatic disease } \\
\text { Trials show early radiotherapy is more effective }\end{array}$ & $\begin{array}{l}\text { Does not allow assessment of response to chemo } \\
\text { Worse compliance to chemotherapy treatment } \\
\text { Delivery of less than full systemic doses? } \\
\text { More acute toxicity? } \\
\text { More late toxicity? }\end{array}$ \\
\hline
\end{tabular}

Disadvantages The main disadvantage for administering systemically active chemotherapy in a consolidation phase is that this strategy does not allow a response to be assessed in terms of chemotherapy, and makes it difficult to decide later whether further chemotherapy is required. In addition, toxicity from CRT may compromise the dose intensity of consolidation chemotherapy.

A study from South Korea (Lee et al, 2002) enrolled patients with Stages II and Stage III rectal cancer following TME surgery. This study aimed to investigate whether early, as opposed to late, postoperative radiotherapy with chemotherapy was the optimal sequence. Radiotherapy started on Day 1 on the first cycle of chemotherapy in the early RT group and Day 1 of the third cycle of chemotherapy in the late RT arm. With a median follow-up of 37 months, $61(22 \%)$ of the 274 eligible patients had experienced a recurrence of their rectal cancer, 23 in the early radiotherapy group $v s 38$ in the late radiotherapy group. The 4-year rate of disease-free survival was $81 \%$ for early radiotherapy and $71 \%$ for late radiotherapy. Both distant metastases and local regional recurrence appeared to show a trend towards being less frequent for early radiotherapy (15 vs $22 \%$ and 2 vs $6 \%$, respectively). However, the 4-year overall survival was similar in both groups (84 vs $82 \%)$. This study seems to confirm the hypothesis that early radiotherapy may be advantageous, and mirrors data suggesting an improved outcome is obtained from early radiotherapy in studies of small-cell lung cancer and NPC (Table 3).

\section{DISCUSSION}

The use of NACT before CRT in other disease sites remains controversial. Four meta-analyses have examined data from the published phase III trials in head and neck cancer, and all have concluded that concurrent rather than neoadjuvant induction chemotherapy regimens lead to improved survival (Stell, 1992;
Munro, 1995; El-Sayed and Nelson, 1996; Pignon et al, 2000). The benefit appears to be $7 \%$ at 2 years and $8 \%$ at 5 years. Two of the meta-analyses (El-Sayed and Nelson, 1996; Pignon et al, 2000) showed no survival advantage to NACT.

Despite the enrolment of large numbers of patients with head and neck cancer in studies testing chemotherapy in the induction setting, and concurrently with radiation, only synchronous CRT has changed outcomes. There are no data to suggest that induction chemotherapy improves local control (Forrestiere et al, 2003). Neoadjuvant induction chemotherapy has shown a benefit in terms of organ preservation in head and neck cancer, but not in terms of overall survival. It remains unclear whether organ preservation is achieved by effective downstaging of the tumour or by selecting patients who are potentially curable by radiation alone. This is not necessarily the same as induction chemotherapy being able to predict the response to subsequent radiotherapy. The routine use of induction chemotherapy followed by radiotherapy in head and neck cancer is therefore not supported by the results of trials.

There is evidence that NACT may improve outcome in terms of disease-free or overall survival is strongest when NACT is administered before surgical resection (Law et al, 1997; MRC, 2002; Allum et al, 2003); although three metanalyses in oesophageal cancer (Malthaner and Fenlon, 2001; Urschel et al, 2002; Malthaner et al, 2004) failed to show a survival benefit for NACT before surgery. Neoadjuvant chemotherapy did not change the number or pattern of local distant or regional recurrence. This advantage does not appear to extend to all patients. Some subsets of patients with an excellent clinical (and pathological) response to NACT appear to have an extended survival time, but despite this observation, overall survival time of the whole group has usually failed to improve.

In NSCLC, the CALGB group established that two cycles of induction chemotherapy using cisplatin and vinblastine followed by radiotherapy to the chest increases median survival time when compared to radiotherapy alone. (Dillman et al, 1996; Sause et al, 
2000). However, although induction chemotherapy reduced the rates of systemic failure, it has failed to improve local control. A meta-analysis has shown an advantage for cisplatin-based induction chemotherapy followed by radiotherapy over radiotherapy alone (Gordon and Vokes, 1999) but an advantage for NACT followed by CRT over CRT alone has not been observed. When the two strategies have been directly compared, concurrent chemotherapy and radiotherapy appears statistically superior to induction chemotherapy although at the price of more severe acute toxicity (Furuse et al, 1999; Curran et al, 2000, 2003).

In bladder cancer, it is possible that there is a small advantage for NACT before cystectomy (Grossman et al, 2003). However, in muscle invasive bladder cancer, the only trial that has compared neoadjuvant and concurrent CRT (RTOG 89-03) has not shown benefit in survival (Shipley et al, 1998).

Ian Tannock's first law of chemotherapy states: 'Tumour response is not an endpoint of patient benefit' (Tannock et al, 1996). There is no evidence that increasing the rate of a clinical or pathological complete response consistently correlates with an increase in disease-free and overall survival. By adding 12 weeks to the overall duration of treatment with 3-4 cycles of induction chemotherapy, tumour cell production could actually increase even if the volume of tumour on CT scanning appears less. Resistance to chemotherapy probably occurs earlier than evidence of tumour progression would lead us to believe (Smith et al, 2002). If NACT is administered before CRT, it may be appropriate to consider using a noncross resistant combination rather than the same drug, for example, oxaliplatin in both schedules. This strategy might overcome the limit of resistant clones developing during concurrent CRT.

In unresectable rectal cancer, or borderline resectable cancers where the circumferential margin is unsafe on preoperative MRI, the most important component is concurrent CRT. In contrast, NACT before surgery for resectable cancers might reduce the risk of subsequent metastatic disease, and is not so concerned with local control. Hence, this is a suitable question to be addressed in future research programmes if surgery alone is the primary treatment. Therefore, we need better initial patient selection, and we need a quick, valid and reliable method of assessing metabolic response or - perhaps better still - resistance to chemotherapy.

\section{REFERENCES}

The Advanced Bladder Cancer (ABC) Meta-analysis Collaboration (2003) Neoadjuvant chemotherapy in invasive bladder cancer: a systematic review and meta-analysis. Lancet 361: 1927-1934

Allum W, Cunningham D, Weeden S, On behalf of the National Cancer Research Institute Upper Gastrointestinal Clinical Study Group (2003) Perioperative chemotherapy in operable gastric and lower oesophageal cancer: a randomised controlled trial (MAGIC trial). J Clin Oncol 21, Proc ASCO Abstract 998

Al-Sarraf M, LeBlanc M, Giri PG, Fu KK, Cooper J, Vuong T, Forastiere AA, Adams G, Sakr WA, Schuller DE, Ensley JF (1998) Chemoradiotherapy $v s$ radiotherapy in patients with advanced nasopharyngeal cancer: phase III randomized Intergroup study 0099. J Clin Oncol 16: $1310-1317$

Bear HD, Anderson S, Brown A, Smith R, Mamounas EP, Fisher B, Margolese R, Theoret H, Soran A, Wickerham DL, Wolmark N, National Surgical Adjuvant Breast and Bowel Project Protocol B-27 (2003) The effect of tumour response of adding sequential preoperative doxecatel chemotherapy to preoperative doxorubicin and cyclophosphamide: preliminary results from National Surgical Adjuvant Breast and Bowel Project B-27. J Clin Oncol 21: 4165-4174

Bosset JF, Calais G, Mineur L, Maingon P, Radosevic-Jelic L, Daban A, Bardet E, Beny A, Ollier A, Collette L (2005a) Preoperative radiation (Preop RT) in rectal cancer: effect and timing of additional chemotherapy (CT) 5-year results of the EORTC 22921 trial. Proc Am Soc Clin Onco 23, (abstract no. 3505)
For locally advanced rectal cancer, current evidence suggests that preoperative CRT provides optimal locoregional control. However, distant failure remains common. The role of adjuvant chemotherapy either before or following CRT in improving disease-free or overall survival has yet to be established, despite evidence that response to induction chemotherapy may predict response to subsequent radiotherapy.

However, experience from other sites (multiple trials in head and neck cancer, NPC, NSCLC, small-cell lung cancer, and cervical cancer) does not support the routine use of NACT either as an alternative, or as additional benefit to CRT. Neoadjuvant chemotherapy does not appear to enhance local control over concurrent CRT or radiotherapy alone. Although there are some data to suggest a reduction in the risk of metastatic disease, the majority of these trials show an advantage for the combination of concurrent chemotherapy and radiotherapy rather than the sequential or induction approach.

\section{CONCLUSIONS}

Our conclusion is that concurrent CRT with early positioning of radiotherapy therefore appears the best option in all disease sites where radiation is the primary local therapy. Neoadjuvant chemotherapy before CRT or radiation in rectal cancer should be used with caution, and only in the context of clinical trials. If NACT is used in this group of patients, a noncross resistant combination is recommended rather than the same drug, for example, oxaliplatin in both schedules. Also the observation of major clinical and pathological downstaging should not obviate the requirement for CRT either pre operatively or post operatively as there will remain a significant risk of local recurrence.

\section{ACKNOWLEDGEMENTS}

Dr Angela K Eggleston for proofreading, comments and general encouragement.
Bosset JF, Calais G, Mineur L, Maingon P, Radosevic-Jelic L, Daban A, Bardet E, Beny A, Briffaux A, Collette L (2005b) Enhanced tumoricidal effect of chemotherapy with preoperative radiotherapy for rectal cancer: preliminary results - EORTC 22921. J Clin Oncol 23: 5620-5627

Brizel DM, Schroeder T, Scher RL, Walenta S, Clough RW, Dewhirst MW, Mueller-Klieser W (2001) Elevated tumour lactate concentrations predict for an increased risk of metastases in head and neck cancers. Int J Radiat Oncol Biol Phys 51: 349-353

Buchholz TA, Tucker SL, Masullo L, Kuerer HM, Erwin J, Salas J, Frye D, Strom EA, McNeese MD, Perkins G, Katz A, Singletary SE, Hunt KK, Buzdar AU, Hortobagyi GN (2002) Predictors of local-regional recurrence after neoadjuvant chemotherapy in mastectomy without radiation. J Clin Oncol 20: $17-23$

Cafiero F, Gipponi M, Lionetto R, P.A.R. Cooperative Study Group (2003) Randomised clinical trial of adjuvant postoperative RT vs sequential postoperative RT plus 5FU and levamisole in patients with stage II-III resectable rectal cancer: a final report. J Surg Oncol 83: 140-146

Calvo E (2002) Systemic chemotherapy for metastatic colorectal cancer: reasons to combine. Clin Colorectal Cancer 2: 170-172

Calvo E, Cyrano F, Gomez SBM et al. (2003) Induction oxaliplatin plus 5FU presupposes the incidence of PTO downstage surgical specimens in $\geqslant \mathrm{CT} 3$ rectal cancer treated with preoperative chemoradiation. Int $J$ Radiat Oncol Biol Phys 57, Suppl. Proc ASTRO Abstract 92

Cassidy J, Tabernero J, Twelves C, Brunet R, Butts C, Conroy T, Debraud F, Figer A, Grossmann J, Sawada N, Schoffski P, Sobrero A, Van Cutsem E, 
Diaz-Rubio E (2004) XELOX (capectiabine plus oxaliplatin); active first line therapy for patients with metastatic colorectal cancer. J Clin Oncol 22: 2084-2091

Cassata A, Stani SC, Alu M et al. (2001) Ongoing phase II trial with two schedules of irinotecan (CPT11) in combination with capecitabine as first-line chemotherapy in patients with advanced colorectal cancer. J Clin Oncol 20: 573

Chan AT, Teo PM, Ngan RK, Leung TW, Lau WH, Zee B, Leung SF, Cheung FY, Yeo W, Yiu HH, Yu KH, Chiu KW, Chan DT, Mok T, Yuen KT, Mo F, Lai M, Kwan WH, Choi P, Johnson PJ (2002) Concurrent chemotherapyradiotherapy compared with radiotherapy alone in locoregionally advanced nasopharyngeal carcinoma: progression-free survival analysis of a phase III randomized trial. J Clin Oncol 20: 2038-2044

Chau I, Allen M, Cunningham D, Brown G, Hill M, Sumpter K, Rhodes A, Wotherspoon A, Norman AR, Hill A, Massey A, Prior Y (2003) Neoadjuvant systemic fluorouracil and mitomycin $\mathrm{C}$ prior to synchronous chemoradiation is an effective strategy in locally advanced rectal cancer. Br J Cancer 88: 1017-1024

Chau I, Cunningham D, Brown G, Tait D et al. (2005) A multidisciplinary approach using Ttwelve weeks of neoadjuvant capecitabine and oxaliplatin followed by synchronous chemoradiation (CRT) and total mesorectal excision (TME) in for MRI defined poor risk locally advanced rectal cancer resulted in promising tumour regression and rapid symptomatic relief. Eur J Cancer Proc ASCO GI 1(Suppl. 5): S93 (abstract 163305)

Chauvergne J, Rohart J, Heron JF, Ayme Y, Berlie J, Fargeot P, George M, Lebrun-Jezekova D, Pigneux J, Chenal C (1990) Randomized trial of initial chemotherapy in 151 locally advanced carcinoma of the cervix (T2b-N1, T3b, MO)]. Bull Cancer 77: 1007-1024

Cho CD, Fisher GA, Halsey J, Jambalos CN, Advani RH, Wakalee H, Lum BL, Sikic BI (2003) A phase II study of gefitinib in combination with FOLFOX-4 (IFOX) in patients with unresectable or metastatic cancer. J Clin Oncol Proc ASCO 22: 265

Choy H, Curran WJ, Scott CB, Bonomi P, Travis P, Haluschak J, Belani CP (2002) Preliminary report of locally advanced multi modality protocol (LAMP) Acr 427 A randomised Phase II study of three chemotherapy regimens with paclitaxel carboplatin and thoracic radiation (TRT) for patient with locally advanced non small cell lung cancer. J Clin Oncol 21, Proc ASCO 291 Abstract 1160

Cunningham D, Humblet Y, Siena S, Khayat D, Bleiberg H, Santoro A, Bets D, Mueser M, Harstrick A, Verslype C, Chau I, Van Cutsern E (2004) Cetuximab monotherapy and cetuximab plus irinotecan in irinotecanrefractory metastatic colorectal cancer. $N$ Engl J Med 351: 337-345

Curran Jr WJ, Scott C, Langer C et al. (2000) Phase III comparison of sequential vs concurrent chemoradiation for patients with unresected stage III non small cell lung cancer (NSCLC): initial report of radiation therapy oncology group (RTOG) 9410. J Clin Oncol 19, 484A Proc ASCO Abstract 1891

Curran Jr WJ, Scott CB, Langer CJ, Komaki R, Lee JS, Hauser B, Movsas B, Wasserman T, Sause W, Cox JD for the Radiation Therapy Oncology Group (2003) Long-term benefit is observed in a Phase III comparison of sequential vs concurrent chemoradiation for patients with unresected stage III non-small cell lung cancer (NSCLC): Report of Radiation Therapy Oncology Group (RTOG) 9410. J Clin Oncol Proc ASCO 29, (abstract 2499)

The Department of Veterans Affairs Laryngeal Cancer Study Group (1991) Induction chemotherapy plus radiation in patients with advanced laryngeal cancer. $N$ Engl J Med 324: 1685-1690

De Pas T, Pelosi G, De Braud F, Veronesi G, , Curigliano G, Leon ME, Danesi R, Noberasco C, d'Aiuto M, Catalano G, Viale G, Spaggiari L (2004) Modulation of epidermal growth factor receptor status by chemotherapy in patients with locally advanced non-small cell lung cancer is rare. J Clin Oncol 22: 4966-4970

Dillman RO, Herndon J, Seagren SL, Eaton Jr WL, Green MR (1996) Improved survival in stage III non-small-cell lung cancer: seven year follow-up of cancer and leukaemia group B (CALGB) 8433 trial. J Natl Cancer Inst 88: $1210-1215$

Dunst J, Reese T, Sutter T, Zuhlke H, Hinke A, Kolling-Schlebusch K, Frings S (2002) Phase I trial evaluating the concurrent combination of radiotherapy and capecitabine in rectal cancer. J Clin Oncol 20: $3983-3991$

Dunst J, Reese T, Debus J, Hoelscher T, Budach W, Rudat V, Wulf J, Mose A, Hinke A (2004) Phase-II-study of preoperative chemoradiation with capecitabine in rectal cancer. J Clin Oncol Proc Am Soc Clin Oncol 23: 260 (abstract 3559)
El-Sayed S, Nelson N (1996) Adjuvant and adjunctive chemotherapy in the management of squamous cell carcinoma of the head and neck region. A meta-analysis of prospective and randomized trials. J Clin Oncol 14: $838-847$

Falcone A, Masi G, Allegrini G, Danesi R, Pfanner E, Brunetti IM, Di Paolo A, Cupini S, Del Tacca M, Conte P (2002) Biweekly chemotherapy with oxaliplatin, irinotecan, infusional fluorouracil, and leucovorin: a pilot study in patients with metastatic colorectal cancer. J Clin Oncol 20: 4006- 4014

Fletcher GH (1980) Basic principles of radiotherapy. Clinical implications of randomness of cell killing where radiation. In Textbook of Radiotherapy, 3rd edn, $\mathrm{p}$ 138. Philadelphia: Lea and Febiger

Fletcher GH (1984) Subclinical disease. Cancer 53: 1274-1284

Fisher B, Brown A, Mamounas E, Wieand S, Robidoux A, Margolese RG, Cruz Jr AB, Fisher ER, Wickerham DL, Wolmark N, DeCillis A, Hoehn JL, Lees AW, Dimitrov NV (1997) Effect of preoperative chemotherapy on loco-regional disease in women with operable breast cancer: findings from National Surgical Adjuvant Breast and Bowel Project B-18. J Clin Oncol 15: $2483-2493$

Fisher B, Bryant J, Wolmark N, Mamounas E, Brown A, Fisher ER, Wickerham DL, Begovic M, DeCillis A, Robidoux A, Margolese RG, Cruz Jr AB, Hoehn JL, Lees AW, Dimitrov NV, Bear HD (1998) Effect of preoperative chemotherapy on the outcome of women with operable breast cancer. J Clin Oncol 16: $2672-2685$

Forrestiere AA, Goepfert TH, Maor M, Pajak TF, Weber R, Morrison W, Glisson B, Trotti A, Ridge JA, Chao C, Peters G, Lee DJ, Leaf A, Ensley J, Cooper J (2003) Concurrent chemotherapy and radiotherapy for organ preservation in advanced laryngeal cancer. N Engl J Med 349: 2091 - 2098

Fowler JF (1991) Rapid repopulation in radiotherapy: a debate on mechanism. The phantom of tumor treatment-continually rapid proliferation unmasked. Radiother Oncol 22: 156-158

Fountzilas G, Zsiadis A, Dafni U, Konstantaras C, Hatzitheoharis G, Liaros A, Athanassiou E, Dombros N, Dervenis C, Basdanis G, Gamvros O, Souparis A, Briasoulis E, Samantas E, Kappas A, Kosmidis P, Skarlos D, Pavlidis N (1999) Postoperative radiation and concomitant bolus fluorouracil with or without additional chemotherapy with fluorouracil and high dose leucovorin in patients with high risk rectal cancer: a randomised phase III study conducted by the Hellenic Cooperative Oncology Group. Ann Oncol 10: 671-676

Frei III E (1982) Clinical cancer research: an embattled species. Cancer 50: $1979-1992$

Frykholm GJ, Pahlman L, Glimelius B (2001) Combined chemo- and radiotherapy $v s$ radiotherapy alone in the treatment of primary, nonresectable adenocarcinoma of the rectum. Int J Radiat Oncol Biol Phys 50: $427-434$

Furuse K, Fukuoka M, Kawahara M, Nishikawa H, Takada Y, Kudoh S, Katagami N, Ariyoshi Y (1999) Phase III study of concurrent vs sequential thoracic radiotherapy in combination with mitomycin, vindesine, and cisplatin in unresectable stage III non-small-cell lung cancer. J Clin Oncol 17: 2692-2699

Fyles AW, Milosevic M, Wong R, Kavanagh MC, Pintilio M, Sun A, Chapman W, Levin W, Manchul L, Keane TJ, Hill RP (1998) Oxygenation predicts radiation response and survival in patients with cervix cancer. Radiother Oncol 48: 149-156

Garden AS (2005) Is there still a role for induction chemotherapy for head and neck cancer? J Clin Oncol 23: 1059-1060

Gerard J, Bonnetain F, Conroy T, Chapet O, Bouche O, Closon-Dejardin MT, Untereiner M, Leduc B, Francois E, Bedenne L (2005) Preoperative (preop) radiotherapy (RT)+5 FU/folinic acid (FA) in T3-4 rectal cancers: results of the FFCD 9203 randomized trial. Proc Am Soc Clin Oncol 23, (abstract no. 3504)

Gastrointestinal Tumor Study Group (1985) Prolongation of the diseasefree survival in surgically treated rectal carcinoma. $N$ Engl J Med 312: $1465-1472$

Glynne-Jones R, Sebag-Montefiore D, McDonald A, Falk S, Maughan T (2004) Preliminary phase II SOCRATES study results: Capecitabine (CAP) combined with oxaliplatin (OX) and preoperative radiation (RT) in patients (pts) with locally advanced rectal cancer (LARC). J Clin Oncol Proc Am Soc Clin Oncol 23: 264 (abstract 3575)

Gordon GS, Vokes EE (1999) Chemoradiation for locally advanced, unresectable NSCLC. New standard of care, emerging strategies. Oncology (Huntington) 13: 1075-1088

Grossman HB, Natale RB, Tangen CM, Speights VO, Vogelzang NJ, Trump DL, deVere White RW, Sarosdy MF, Wood Jr DP, Raghavan D, Crawford ED (2003) Neoadjuvant chemotherapy plus cystectomy compared to 
cystectomy alone for locally advanced bladder cancer. N Engl J Med 349: $859-866$

Guillem JG, Moore HG, Akhurst T, Klimstra DS, Ruo L, Mazumdar M, Minsky BD, Saltz L, Wong WD, Larson S (2004) Sequential preoperative fluorodeoxyglucose-positron emission tomography assessment of response to preoperative chemoradiation: a means for determining longterm outcomes of rectal cancer. J Am Coll Surg 199: 1-7

Hall EJ (2000) Radiobiology for the Radiologist. Philadelphia, Lipincott Williams and Wilkins, chapter 1

Hoff PM, Janjan N, Saad ED, Skibber J, Crane C, Lassere Y, Cleary KR, Benner S, Randolph J, Abbruzzese JL, Pazdur R (2000) Phase I trial of preoperative oral Uracil and Tegafur plus leucovorin and radiation therapy in rectal cancer. J Clin Oncol 18: 3529-3534

Hofheinz R, Von Gerstenberg-Helldorf B, Wenz F, Gnad U, KrausTiefenbacher U, Muldner A, Hehlmann R, Post S, Hochhaus A, Willeke F (2005) Phase I trial of capecitabine and irinotecan in combination with concurrent radiotherapy for neoadjuvant therapy of rectal cancer. J Clin Oncol 23: $1350-1357$

International Collaboration of Trialists on behalf of the Medical Research Council Advanced Bladder Cancer working party/EORTC (1999) Neoadjuvant cisplatin methotrexate and vinblastine: chemotherapy for muscle invasive bladder cancer: a randomised controlled study. Lancet 353: $533-540$

James R, Meadows H (2003) The second UK phase III anal cancer trial of chemoradiation and maintenance therapy (ACT II): preliminary results on toxicity and outcome. J Clin Oncol 22: 287 (abstract 1151)

Kapiteijn E, Marijnen CA, Nagtegaal ID, Putter H, Steup WH, Wiggers T, Rutten HJ, Pahlman L, Glimelius B, van Krieken JH, Leer JW, van de Velde CJ, Dutch Colorectal Cancer Group (2001) Preoperative radiotherapy combined with total mesorectal excision for resectable rectal cancer. $N$ Engl J Med 345: 638-646

Kennedy AS, Kwok Y, Batko-Yovino S et al. (2004) A phase I study of preoperative capecitabine, irinotecan concurrent with radiation therapy for resectable rectal cancer. Proc Am Soc Clin Oncol Gastrointest Cancers Sympo (abstract 268)

Kim J-S, Kim J-S, Cho M-L, Song KS, Yoon WH (2002) Preoperative chemoradiation using oral capecitabine in locally advanced rectal cancer. Int J Radiat Oncol Biol Phys 54: 403-408

Krook JE, Moertel CG, Gunderson LL, Wieand HS, Collins RT, Beart RW, Kubista TP, Poon MA, Meyers WC, Mailliard JA (1991) Effective surgical adjuvant therapy for high-risk rectal carcinoma. $N$ Engl J Med 324: $709-715$

Kumar L, Kaushal R, Nandy M, Biswal BM, Kumar S, Kriplani A, Singh R, Rath GK, Kochupillai V (1994) Chemotherapy followed by radiotherapy $v s$ radiotherapy alone in locally advanced cervical cancer: a randomized study. Gynecol Oncol 54: 307-315

Kummermehr J, Dorr W, Trott KR (1992) Kinetics of accelerated repopulation in normal and malignant squamous epithelia during fractionated therapy. BJR Suppl 24: 193-199

Law S, Fok M, Chow S, Chu KM, Wong J (1997) Preoperative chemotherapy $v s$ surgical therapy alone for squamous cell carcinoma of the esophagus: a prospective randomized trial. J Thorac Cardiovasc Surg 114: $210-217$

Leborgne F, Leborgne JH, Doldan R, Zubizarreta E, Ortega B, Maisonneuve J, Musetti E, Hekimian L, Mezzera J (1997) Induction chemotherapy and radiotherapy of advanced cancer of the cervix: a pilot study and phase III randomized trial. Int J Radiat Oncol Biol Phys 37: 343-350

Lee JH, Lee JH, Ahn JH et al. (2002) Randomised trial of post-operative adjuvant therapy in stage II and III rectal cancer to find the optimal sequence of chemotherapy and radiotherapy - a preliminary report. $J$ Clin Oncol 20: $1751-1758$

Lefevre JL, Chevalier D, Luboinski B, Kirkpatrick A, Collette L, Sahmoud T (1996) Larynx preservation in pyriform sinus cancer: preliminary results of a European Organization for Research and Treatment of Cancer phase III trial. EORTC Head and Neck Cancer Cooperative Group. J Natl Cancer Inst 88: 890-899

Lin JC, Jan JS, Hsu CY, Liang WM, Jiang RS, Wang WY (2003) Phase III study of concurrent chemoradiotherapy $v s$ radiotherapy alone for advanced nasopharyngeal carcinoma: positive effect on overall and progression-free survival. J Clin Oncol 21: 631-637

Maehara Y, Sakaguchi Y, Emi Y, Kusumoto T, Kohnoe S, Mori M, Sugimachi K (1990) Primary and metastatic liver lesions of clinical colorectal cancer differ in chemosensitivity. Int J Colorect Dis 5: 87-89

Makris A, Powles T, Ashley SE, Chang J, Hickish T, Tidy VA, Nash AG, Ford HT (1998) A reduction in the requirement for mastectomy in a randomized trial of neoadjuvant chemoendocrine therapy in primary breast cancer. Ann Oncol 9: 1179-1184

Malthaner R, Fenlon D (2001) Preoperative chemotherapy for resectable thoracic oesophageal cancer (Cochrane review). Cochrane database Syst Rev CD001556

Malthaner R, Wong RKS, Rumble RB et al. (2004) Neoadjuvant or adjuvant therapy for resectable oesophageal cancer: a systematic review and metaanalysis. BMC Med 2: 35

Mauriac L, Durand M, Avril A, Dilhurdy JM (1991) Effect of primary chemotherapy in conservative treatment breast cancer patients with operable tumours larger than $3 \mathrm{~cm}$. Results of a randomised trial in a single centre. Ann Oncol 2: 347-354

Medical Research Council Oesophageal Cancer Working Party (2002) Surgical resection with or without preoperative chemotherapy in oesophageal cancer: a randomised controlled trial. Lancet 359: $727-733$

Michell EP, Anne P, Fry R, Ahmad N, Boman B, Edmunston T, Rakinic J, Goldstein S, Rose L, Palazzo J, Cagir B, Kovatich A, Hauck W, Fishel R, Bonanni R, Hoey D, Rose D, Curran W (2001) Combined modality therapy of locally advanced or recurrent adenocarcinoma of the rectum: report of a phase I trial of chemotherapy (CT) with CPT11, 5FU and concomitant irradiation (RT). J Clin Oncol 20: 131a

Milas L, Hunter N, Mason K, Milross CG, Saito Y, Peters LJ (1995) Role of reoxygenation in induction of enhancement of tumor radioresponse by paclitaxel. Cancer Res 55: 3564-3568

Munro AJ (1995) An overview of randomised controlled trials of adjuvant chemotherapy in head and neck cancer. Br J Cancer 71: 83-91

Murray N, Coy P, Pater JL, Hodson I, Arnold A, Zee BC, Payne D, Kostashuk EC, Evans WK, Dixon P et al. (1993) Importance of timing for thoracic irradiation in the combined modality treatment of limited-stage small-cell lung cancer. The National Institute of Canada Clinical Trials Group. J Clin Oncol 11: 336-344

Nordsmark M, Overgaard J (2000) A confirmatory prognostic study on oxygenation status and loco-regional control in advanced head and neck squamous cell carcinoma treated by radiation therapy. Radiother Oncol 57: $39-43$

Perez CA, Brady LW, Roti JL (1998) Overview. In Principles and Practice of Radiation Oncology, Perez CA, Brady LW (eds), 3rd edn, pp 1-78. Philadelphia: Lipincott-Raven

Peters LJ, Withers HR (1997) Applying radiobiological principles to combined modality treatment of head and neck cancer - the time factor. Int J Radiat Oncol Biol Phys 39: 831-836

Pignon JP, Bourhis J, Domenge C, Designe L (2000) Chemotherapy added to locoregional treatment for head and neck squamous-cell carcinoma: three meta-analyses of updated individual data. MACH-NC Collaborative Group. Meta-analysis of chemotherapy on head and neck cancer. Lancet 355: $949-955$

Rich TA, Skibber JM, Ajani JA, Buchholz DJ, Cleary KR, Dubrow RA, Levin B, Lynch PM, Meterissian SH, Roubein LD (1995) Preoperative infusional chemoradiation therapy for stage III rectal cancer. Int J Radiat Oncol Biol Phys 32: $1025-1029$

Rodel C, Grabenbauer GG, Papadopoulos T, Hohenberger W, Schmoll HJ, Sauer R (2003) Phase I/II trial of capecitabine oxaliplatin and radiation in rectal cancer. J Clin Oncol 21: 3098-3104

Rohatgi PR, Swisher SG, Correa AM, Wu TT, Liao Z, Komaki R, Walsh G, Vaporciyan A, Lynch PM, Rice DC, Roth JA, Ajani JA (2005) Failure patterns correlate with the proportion of residual carcinoma after preoperative chemoradiotherapy for carcinoma of the oesophagus. Cancer 104: 1349-1355

Rosenthal DI, Catalano P, Haller D et al. (2002) ECOG 1297: A phase I study of preoperative radiation therapy (RT) with concurrent protracted continuous infusion 5FU and dose escalating oxaliplatin followed by surgery, adjuvant $5 \mathrm{FU}$ and leucovorin for locally advanced (T3/T4) rectal adenocarcinoma. J Clin Oncol 22: 273 (abstract 1094)

Saltz L, Meropol NJ, Loehrer PJ et al. (2002) Phase II trial of IMC-C225 (Erbitux $^{\mathrm{TM}}$ ) has activity in CPT-11-refractory colorectal cancer (CRC) that expresses epidermal growth factor receptor (EGFR). J Clin Oncol Proc ASCO 21, (abstract 504)

Saltz LB, Meropol NJ, Loehrer Sr PJ, Needle MN, Kopit J, Mayer RJ (2004) Phase II trial of cetuximab in patients with refractory colorectal cancer that expresses the epidermal growth factor receptor. J Clin Oncol 22(7): $1201-1208$

Sauer R, Becker H, Hohenberger W, Rodel C, Wittekind C, Fietkau R, Martus P, Tschmelitsch J, Hager E, Hess CF, Karstens JH, Liersch T, Schmidberger H, Raab R (2004) German Rectal Cancer Study Group. 
Preoperative $v s$ postoperative chemoradiotherapy for rectal cancer. $N$ Engl J Med 351: $1731-1740$

Sause W, Kolesar P, Taylor S IV, Johnson D, Livingston R, Komaki R, Emami B, Curran Jr W, Byhardt R, Dar AR, Turrisi III A (2000) Final results of phase III trial in regionally advanced unresectable nonsmall cell lung cancer: Radiation Therapy Oncology Group, Eastern Cooperative Oncology Group, and Southwest Oncology Group. Chest 117: $358-364$

Scholl SM, Fourquet A, Asselain B, Pierga JY, Vilcoq JR, Durand JC, Dorval T, Palangie T, Jouve M, Beuzeboc P (1994) Neoadjuvant vs adjuvant chemotherapy in premenopausal patients with tumours considered too large for breast conserving surgery: preliminary results of a randomised trial. Eur J Cancer 30A: 645-652

Shipley WU, Winter KA, Kauffman DS, Lee WR, Heney NM, Tester WR, Donnelly BJ, Venner PM, Perez CA, Murray KJ, Doggett RS, True LD (1998) Phase III trial of neoadjuvant chemotherapy in patients with invasive bladder cancer treated with selective bladder preservation by combined radiation therapy and chemotherapy: initial results of Radiation Therapy Oncology Group 89-03. J Clin Oncol 16: 3576-3583

Smith IC, Heys SD, Hutcheon AW, Miller ID, Payne S, Gilbert FJ, Ah-See AK, Eremin O, Walker LG, Sarkar TK, Eggleton SP, Ogston KN (2002) Neoadjuvant chemotherapy in breast cancer: significantly enhanced response with docetaxel. J Clin Oncol 20(6): 1456-1466

Souhami L, Gil R, Allan SE, Canary PC, Araujo CM, Pinto LH, Silveira TR (1991) A randomized trial of chemotherapy followed by pelvic radiation therapy in stage IIIB carcinoma of the cervix. J Clin Oncol 9: 970-997

Spaulding MB, Fischer SG, Wolf GT (1994) Tumor response, toxicity, and survival after neoadjuvant organ-preserving chemotherapy for advanced laryngeal carcinoma. The Department of Veterans Affairs Cooperative Laryngeal Cancer Study Group. J Clin Oncol 12: $1592-1599$

Stell PM (1992) Adjuvant chemotherapy in head and neck cancer. Semin Radiat Oncol 2: $195-205$

Sundfor K, Trope CG, Hogberg T, Onsrud M, Koern J, Simonsen E, Bertelsen K, Westberg R (1996) Radiotherapy and neoadjuvant chemothewrapy for cervix carcinoma. A randomized multicenter study of sequential cisplatin and 5-fluorouracil and radiotherapy in advanced cervical carcinoma stage 3B and 4A. Cancer 77: 2371-2378

Tabernero JM, Van Cutsem E, Sastre J, Cervantes A, Van Laethem JL, Humblet Y, Soulie P, Corretge S, Mueser M, De Gramont A (2004) An international phase II study of cetuximab in combination with oxaliplatin/5-fluorouracil (5FU)/folinic acid (FA) (FOLFOX-4) in the first-line treatment of patients with metastatic colorectal cancer (CRC) expressing epidermal growth factor receptor (EGFR). Preliminary results. J Clin Oncol Proc ASCO 22: 14S (abstract 3512)

Taghian AG, Abi-Raad R, Asaad SI, Casty A, Ancukiewicz M, Yeh E, Molokhia P, Attia K, Sullivan T, Kuter I, Boucher Y, Powell SN (2005) Paclitaxel decreases the interstitial fluid pressure and improves oxygenation in breast cancer cancers in patients treated with neoadjuvant chemotherapy:clinical implications. J Clin Oncol 23: 1951-1961

Tannock IF, Osoba D, Stockler MR, Ernst DS, Neville AJ, Moore MJ, Armitage GR, Wilson JJ, Venner PM, coppin CM, Murphy KC (1996) Chemotherapy with mitoxantrone plus prednisone or prednisone alone for symptomatic hormone-resistant prostate cancer: a Canadian randomised trial with palliative end points. J Clin Oncol 14: 1756-1764

Tattersall MH, Lorvidhaya V, Vootiprux V, Cheirsilpa A, Wong F, Azhar T, Lee HP, Kang SB, Manalo A, Yen MS et al. (1995) Randomized trial of epirubicin and cisplatin chemotherapy followed by pelvic radiation in locally advanced cervical cancer. Cervical Cancer Study Group of the Asian Oceanian Clinical Oncology Association. J Clin Oncol 13: 444-451

Tattersall MH, Ramirez C, Coppleson M (1992) A randomized trial comparing platinum-based chemotherapy followed by radiotherapy $v s$ radiotherapy alone in patients with locally advanced cervical cancer. Int $J$ Gynecol Cancer 2: 244-251

Tepper JE, O'Connell M, Niedzwiecki D, Hollis DR, Benson 3rd AB, Cummings B, Gunderson LL, Macdonald JS, Martenson JA, Mayer RJ (2002) Adjuvant therapy in rectal cancer:nalysis of stage, sex, and local control - final report of intergroup 0114. J Clin Oncol 20: 1744-1750

Tournigand C, Andre T, Achille E, Lledo G, Flesh M, Mery-Mignard D, Quinaux E, Couteau C, Buyse M, Ganem G, Landi B, Colin P, Louvet C, de Gramont A (2004) FOLFIRI followed by FOLFOX6 or the reverse sequence in advanced colorectal cancer: a randomized GERCOR study. J Clin Oncol 22(2): 229-237

Trott KR (1999) The mechanisms of acceleration of repopulation in squamous epithelia during daily irradiation. Acta Oncol 38: 153-157

Tveit KM, Guldvog I, Hagen S, Trondsen E, Harbitz T, Nygaard K, Nilsen JB, Wist E, Hannisdal E (1997) Randomized controlled trial of postoperative radiotherapy and short-term time-scheduled 5-fluorouracil against surgery alone in the treatment of Dukes B and C rectal cancer. Norwegian Adjuvant Rectal Cancer Project Group. Br J Surg 84: $1130-1135$

Urschel JD, Vasan H, Blewett CJ (2002) A meta-analysis of randomized controlled trials that compared neoadjuvant chemotherapy and surgery to surgery alone for resectable esophageal cancer. Am J Surg 183: 274-279

van der Hage JA, van der Velde CJ, Julien JP, Tubiana-Hulin M, Vandervelden C, Duchateau L (2001) Preoperative chemotherapy in primary operable breast cancer: results from the European Organization for Research and Treatment of Cancer Trial 10902. J Clin Oncol 19: $4224-4237$

Von Hoff DD, Clark GM, Forsyth BJ, Cowan JD (1986) Simultaneous in vitro drug sensitivity testing on tumours from different sites in the same patient. Cancer 58: 1007-1013

Walenta S, Wetterling M, Lehrke M, Schwickert G, Sundfor K, Rofstad EK, Mueller-Klieser W (2000) High lactate levels predict likelihood of metastases, tumour recurrence and restricted patient survival in human cervical cancers. Cancer Res 60: 916-921

Withers HR, Taylor JMG, Maciejiewski B (1988) The hazard of accelerated tumour clonogen repopulation during radiotherapy. Acta Oncol 27: $131-146$

Wolmark N, Wieand HS, Hyams DM, Colangelo L, Dimitrov NV, Romond EH, Wexler M, Prager D, Cruz Jr AB, Gordon PH, Petrelli NJ, Deutsch M, Mamounas E, Wickerham DL, Fisher ER, Rockette H, Fisher B (2000) Randomized trial of postoperative adjuvant chemotherapy with or without radiotherapy for carcinoma of the rectum: National Surgical Adjuvant Breast and Bowel Project Protocol R-02. J Natl Cancer Inst 92: $361-362$

Wolmark N, Wang J, Mamounas E, Bryant J, Fisher B (2001) Preoperative chemotherapy in patients with operable breast cancer: nine year results from National Surgical Adjuvant Breast and Bowel Project B-18. J Natl Cancer Inst 19: 96-102

Ychou M, Conroy E, Seitz JF, Gourgou S, Hua A, Mery-Mignard D, Kramar A (2003) An open phase I study assessing the feasibility of the triple combination: oxaliplatin plus irinotecan plus leucovorin/5fluorouracil every 2 weeks in patients with advanced solid tumours. Ann Oncol 14: $481-489$ 